\title{
Nanocomposites Materials Generated from a Spray.
}

\author{
R.F.C. Marques, J.M.A. Caiut, C.O. Paiva-Santos, S.J.L. Ribeiro, and Y. Messaddeq \\ Institute of Chemistry, UNESP, Araraquara-SP, 14801-970, Brazil \\ C. Garcia, D. Neumeyer, H. Dexpert, M. Verelst, and J. Dexpert-Ghys \\ Centre d'Elaboration de Matériaux et d'Etudes Structurales UPR 8011, \\ CNRS-Université Paul Sabatier, 29 Rue Jeanne Marvig, F 31055 Toulouse Cedex 4, France*
}

(Received on 1 July, 2008)

\begin{abstract}
The Spray Pyrolysis (SP) process has been employed at moderate temperature (470-970 K) for the synthesis of micro- and nano-particles of hydrated metal oxides and of related nanocomposites. It has been applied to iron nitrate solutions, without or with the addition of sodium chloride as a flux. After removal of the flux, nanocomposites of ferrihydrite $\left(5 \mathrm{Fe}_{2} \mathrm{O}_{3}, 9 \mathrm{H}_{2} \mathrm{O}\right) /$ hematite $\left(\alpha-\mathrm{Fe}_{2} \mathrm{O}_{3}\right) /$ and an amorphous $\mathrm{Fe}_{2} \mathrm{O}_{3}$ are obtained, with surface area $140 \mathrm{~m}^{2} / \mathrm{g}$. It has been applied also to a sol of Aluminum-tri-sec-butoxide, without or with activation by europium or terbium ions. Boehmite $(\gamma-\mathrm{AlOOH})$ powders are synthesized at $470 \mathrm{~K}$, with surface area equal to $180 \mathrm{~m}^{2} / \mathrm{g}$. Transition alumina $\left(\gamma-\mathrm{Al}_{2} \mathrm{O}_{3}\right)$ are synthesized at $970 \mathrm{~K}$. Nanocomposites made by reaction of the boehmite or $\gamma-\mathrm{Al}_{2} \mathrm{O}_{3}$ particles with the amino acid asparagin (ASN) have been prepared and characterized. The luminescence of the $\mathrm{Eu}^{3+}$ or $\mathrm{Tb}^{3+}$ doped nanocomposites has been investigated: they can be considered as bio-compatible luminescent nanoparticles.
\end{abstract}

Keywords: Spray-pyrolysis, Nano-powders, Ferrihydrite, Hematite, Boehmite, Alumina.

\section{INTRODUCTION}

Spray Pyrolysis (SP) is an aerosol process commonly used to form a wide variety of materials in powder form including metals, metal oxides, ceramics, superconductors, etc ... One of the major advantages of SP is the flexibility: pyrolysis may be conducted at high temperatures ( $1270 \mathrm{~K}$ or more) so that high temperature phases may be achieved in one step. Alternatively, the whole process may also be conducted at lower temperature: it may then be described as a rapid drying of the spray. In the past years, we intended to take benefit of this flexibility in order to synthesize sub-micrometric or nanometric particles in a wide range of chemical compositions and considering a wide range of possible applications [1-6] Submicronic phosphor powders for plasma display applications were synthesized and post-annealed $[1,2]$, nanometric powders of zincite $\mathrm{ZnO}$ for cosmetic applications were synthesized by SP of mixtures of zinc and lithium (or sodium) nitrates [3]; sub-micronic particles of boehmite (AlOOH) were obtained by spray-drying of an aluminium alcoolate[4], these particles spontaneously dispersed in water to form stable suspensions of boehmite nanoparticles that could be doped with photo luminescent lanthanide ions, then surface-modified to become bio-compatible $[5,6]$. The purpose of the present paper is to show how SP, conducted at moderate temperature,may be used for the synthesis of highly divided, highly reactive metal (here $\mathrm{Fe}$ or $\mathrm{Al}$ ) hydroxides and oxides powders.

Iron oxyhydroxides and oxides are of technological importance as catalytic materials, sorbents, pigments, floculents, coatings, gas sensor and ion exchanger [7]. Among them, ferrihydrite is a natural material present in many near surface environments [8, 9]. Due to its high surface area and reactivity, ferrihydrite plays an important role in the sequestration of contaminants from groundwater. Adsorption on ferrihydrite is commonly used to arsenate sequestration from soils,

*Electronic address: jeannette. dexpert@cemes.fr groundwater and surface water system [10]. Ferrihydrite is the first phase to precipitate during hydrolysis of $\mathrm{Fe}^{3+}$ ions in solution. Its rough formula is $5 \mathrm{Fe}_{2} \mathrm{O}_{3}, 9 \mathrm{H}_{2} \mathrm{O}$. Its exact formula is still being debated, as is controversial also its exact crystal structure (see for instance [11, 12]). This is not really surprising since the synthesis conditions have a great impact on the average crystal size and on the reactivity towards water of these nanocrystalline materials. Among the huge literature dealing with structural characterizations, we selected the multiple structural phases model described by Jansen et. al. [13] and revisited by Y. Cudennec et al. [14]. Ferrihydrite is metastable and generally considered as goethite $\alpha$ $\mathrm{FeO}(\mathrm{OH})$ or hematite $\alpha-\mathrm{Fe}_{2} \mathrm{O}_{3}$ precursor, depending on $\mathrm{pH}$ and/or temperature. Hematite is the end-product of thermal decomposition of ferrihydrite in oxidative atmosphere [15]. Hematite has been demonstrated as a potential catalyst for many environmental application including oxidative removal of carbon monoxide or methane combustion. Currently in the market, NANOCAT superfine $\mathrm{Fe}_{2} \mathrm{O}_{3}$ nanoparticles (supplied by Mach-I Inc.) are composed of a mixture of amorphous and crystalline structures. The higher catalytic activity of NANOCAT than others commercially available $\mathrm{Fe}_{2} \mathrm{O}_{3}$ (hematite) is ascribed to its amorphous constituents.

The aluminium oxyhydroxide boehmite $\gamma-\mathrm{AlOOH}$ is the most important precursor of the transition aluminas. Transition aluminas are widely used in the industry of adsorbents and catalysts $[16,17]$. $\gamma$-AlOOH is traditionally prepared by i) solid state decomposition of gybsite, ii) precipitation from acidic or basic aluminium aqueous solutions, iii) sol gel procedures from aluminium alcoholates. The third method allows the preparation of very pure boehmite, although from more expensive chemicals. A very common procedure was first described in $[18,19]$. It consists of aluminium alkoxide hydrolysis followed by peptization to a clear sol, the gel formation, and then the gel drying to get hydrated boehmite. Further pyrolysis at higher temperature gives porous alumina. The control of the drying conditions is necessary to control the properties of the boehmite powder. The names pseudoboehmite or nano crystalline boehmite are used in con- 
trast to microcrystalline or well crystallized boehmite. The nanocrystalline boehmites exhibit crystallite size less than 10 $\mathrm{nm}$, defects and numerous adsorbed water molecules: these features strongly depend on the preparation conditions [20]. The so-called transition aluminas, refer to the group of partially dehydrated aluminium hydroxides other than anhydrous $\alpha$-alumina (corundum). The diffuse characteristic of the powder patterns reflects a high degree of structural disorder in the transition aluminas. The transition aluminas are widely used in industry as adsorbents, catalysts or catalyst carriers, coatings and soft abrasives because of their fine particle size, high surface area and the catalytic activities of their surfaces. $\gamma$ $\mathrm{Al}_{2} \mathrm{O}_{3}$ is the first transition alumina obtained by thermal decomposition of the boehmite[21, 22].

One aim of this work is to investigate the possibility to obtain by $\mathrm{SP} \alpha-\mathrm{Fe}_{2} \mathrm{O}_{3}$ /ferrihydrite spherical and mesoporouslike structures. Consequently, we propose an alternative material to commercially available NANOCAT product. Nanocomposites particles are generated from a precursor solution containing $\mathrm{Fe}\left(\mathrm{NO}_{3}\right)_{3}, 9 \mathrm{H}_{2} \mathrm{O}$ and $\mathrm{NaCl}$. Herein are investigated the influence of $\mathrm{NaCl}$ in the iron nitrate precursor solution and of other operating conditions on the nature, the structure, the morphology and the crystallinity of the powders. Another aim is to synthesize by SP boehmite and transition aluminas as highly divided nanometric powders. The nanometric and/or sub-micronic hydrated aluminas are highly reactive, especially towards amino acids (AA). The nanocomposite hybrids made of boehmite or alumina with the asparagin (ASN) have been studied and characterized as described herein. One possible application of these nanoparticles is luminescent bio-labelling after their activation by an emissive lanthanide ion $\left(\mathrm{Eu}^{3+}, \mathrm{Tb}^{3+}\right)$. Data concerning their optical spectroscopy are described and discussed.

\section{EXPERIMENTAL}

Samples are prepared by the spray pyrolysis process which is based on an aerosol formation. An intense ultrasonic source close to the liquid surface will produce a geyser, resulting in an aerosol formation due to cavitations effects on the liquid surface. The aerosol, formed by the precursor droplets in an air stream, is conducted through a dry zone at 370$1390 \mathrm{~K}$, then a decomposition-densification zone which can be maintained in the range $570-1470 \mathrm{~K}$. Collection of the dried powders is achieved by a home made electrostatic collector. The ultrasonic generator operates at $2.4 \mathrm{MHz}$. The adjustable operating parameters are the flow rate (by which the residence time in the furnace is controlled), the temperature in decomposition zone $\mathrm{T}_{\text {syn }}$, and of course the nature of the precursor solution. Spheres composed by $\alpha-\mathrm{Fe}_{2} \mathrm{O}_{3} /$ ferrihydrite nanoparticles are obtained through spray pyrolysis of a precursor solution containing $\mathrm{Fe}\left(\mathrm{NO}_{3}\right)_{3}, 9 \mathrm{H}_{2} \mathrm{O}$ and $\mathrm{NaCl}$ as a flux. The idea is to obtain spheres constituted of two phases: the iron oxide phase and a water soluble phase $(\mathrm{NaCl})$. The as-prepared composite spheres are washed several times in water to remove $\mathrm{NaCl}$ and the iron oxide is recovered, as schematized in Figure $1 . \mathrm{T}_{\text {syn }}$ is fixed at 660 or $820 \mathrm{~K}$. For the alumina-based compositions, the precursor solution is prepared following the methodology established by B. Yoldas $[18,19]$. A stable sol of Aluminum-tri-sec-butoxide is diluted

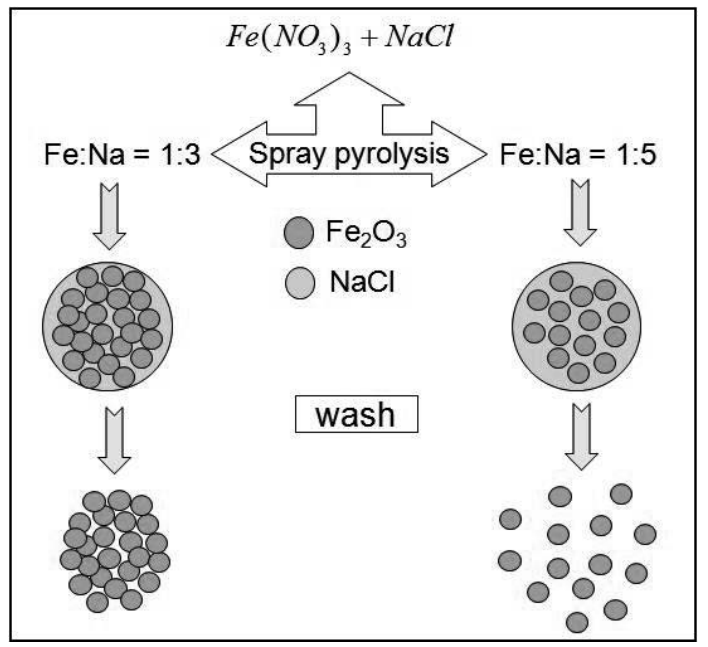

FIG. 1: schematic representation of iron oxide nanoparticles synthesized by $\mathrm{SP}$ using a soluble flux $(\mathrm{NaCl})$.

in water to concentration $0.2 \mathrm{~mol} / \mathrm{L}$ of $\mathrm{Al}^{3+}$, and poured into the vessel over the piezoelectric pellet. $\mathrm{T}_{\text {syn }}$ is fixed at 470 or $970 \mathrm{~K}$. Activation by optically active ions $\left(\mathrm{Eu}^{3+}\right.$ orTb $\left.{ }^{3+}\right)$ is achieved by addition of $2 \%([\mathrm{Eu}]$ or $[\mathrm{Tb}]) /[\mathrm{Al}]$ to the distilled water before addition of the aluminum-tri-sec-butoxide. For all SP syntheses, the air flow is $0.3 \mathrm{~m}^{3} / \mathrm{h}$, the residence time in the drying zone is 3-4 seconds and about 6-8 sec in the decomposition-densification zone. Amino-Acids - aluminoxanes nanocomposites have been obtained by dispersing the aluminium oxyhydroxide or oxide particle from SP in asparagines water solutions, under agitation for 12 hours. Adsorption/desorption isotherms have been performed by using a Belsorp-mini (BEL Japan Inc. apparatus), between 0 and $99 \mathrm{P} / \mathrm{P}_{0}$ of nitrogen and at $77 \mathrm{~K}$ after a pre-treatmet at $353 \mathrm{~K}$ under vacuum during 2 hours. Thermal analyses have been performed in a Labsys TG/DTA (SETARAM) analyser in an alumina crucible at $5 \mathrm{~K} / \mathrm{min}$, under oxygen. The size, the morphology and the crystalline structure of the particles have been studied by transmission electron microscopy (TEM) on a Philips CM12 microscope. The crystalline structures of samples have been investigated by $\mathrm{X}$ ray powder diffraction (Seifert XRD 3000 diffractometer) and the quantitative phases analysis obtained by Rietveld refinements [23] using the program GSAS [24]. In order to obtain a internal standard without microstrain and with a high average crystallite size, the $99,99 \%$ cerium oxide is fired at $1570 \mathrm{~K}$ for $48 \mathrm{~h}$. Room temperature luminescence excitation and emission spectra have been measured by a Hitachi Fl100 spectrofluorimeter at $2.5 \mathrm{~nm}$ spectral resolution.

\section{RESULTS AND DISCUSSION}

\section{A. Iron oxyhydroxides and oxides.}

Sample FE1 has been prepared without $\mathrm{NaCl}$ in the precursor solution. As expected in spray pyrolysis synthesis under the selected operating conditions, the particles are spherical and their diameters fall in the range 100 to $2000 \mathrm{~nm}$. One TEM image of sample FE1 is displayed in figure 2a. All 


\begin{tabular}{|c|c|c|c|c|c|}
\hline sample & {$[\mathrm{Fe}]$} & {$[\mathrm{Na}]$} & $\mathrm{Fe}: \mathrm{Na}$ & $\mathrm{T}_{\text {syn }}$ & XRD \\
\hline FE1 & 0.15 & - & - & 820 & HEM \\
\hline FE2 & 1.0 & - & - & 820 & HEM \\
\hline FE3 & 1.5 & - & - & 820 & HEM \\
\hline FENA1 & 0.15 & 0.45 & $1: 3$ & 820 & $\mathrm{HEM}+\mathrm{FEH}+\mathrm{NaCl}$ \\
\hline FENA2 & 0.15 & 0.45 & $1: 3$ & 660 & $\mathrm{HEM}+\mathrm{FEH}+\mathrm{NaCl}+\mathrm{NaNO}_{3}$ \\
\hline FENA3 & 0.10 & 0.50 & $1: 5$ & 820 & $\mathrm{HEM}+\mathrm{FEH}+\mathrm{NaCl}$ \\
\hline
\end{tabular}

TABLE I: experimental synthesis conditions for iron-based samples: $[\mathrm{Fe}]$ and $[\mathrm{Na}]$ in mol. $\mathrm{L}^{-1}, \mathrm{~T}_{\text {syn }}$ in $\mathrm{K}, \mathrm{XRD}$ : crystalline phases identified $\left(\mathrm{HEM}=\alpha-\mathrm{Fe}_{2} \mathrm{O}_{3}, \mathrm{FEH}=\right.$ ferrihydrite)

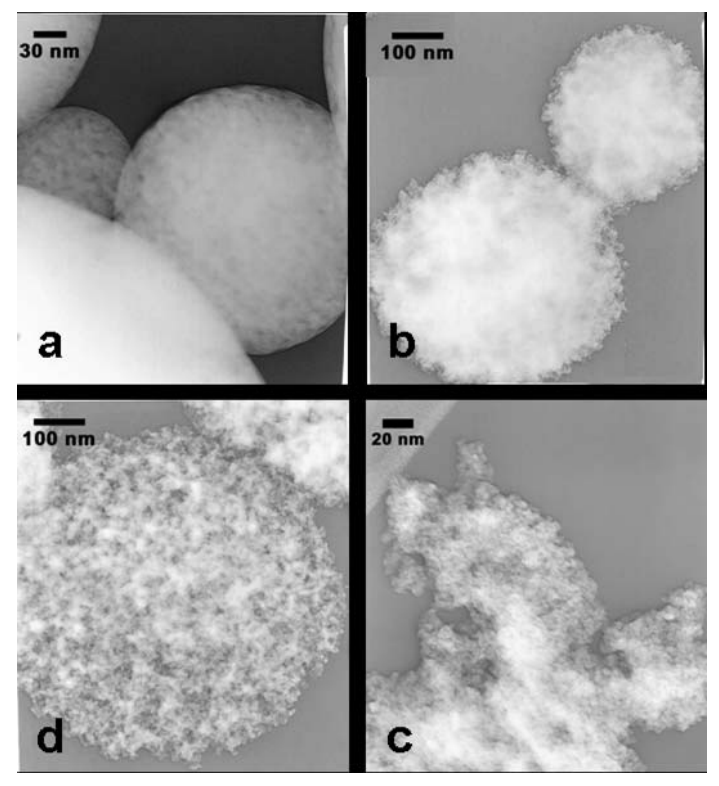

FIG. 2: TEM images of samples FE1(a); FeNa2(b); FENA2-washed (c), and FENA1-washed (d)

XRD peaks observed for this sample may be indexed with hematite ( $\alpha-\mathrm{Fe}_{2} \mathrm{O}_{3}-\mathrm{PDF}$ no 89-2810), as shown in figure 3 . The XRD patterns of as obtained samples FENA 1-3 display well defined narrow peaks superposed on broad components. Hematite is detected, together with $\mathrm{NaCl}$ for the three samples and with $\mathrm{NaNO}_{3}$ in sample FENA2 synthesized at $660 \mathrm{~K}$. This results from the reaction of nitrate species freed by the iron precursor with sodium ions. Nitrate species are evolved when the synthesis is conducted at higher temperature (820 $\mathrm{K})$. These observations prove the complexity of the SP synthesis during which occur in a limited range of time the solute precipitation, the solvent evaporation and chemical reactions between the constituents in each droplet [25]. After water washing, XRD patterns of soluble phases $\mathrm{NaCl}$ and $\mathrm{NaNO}_{3}$ are not observed, the diffraction diagrams exhibit the peaks of $\alpha-\mathrm{Fe}_{2} \mathrm{O}_{3}$ and broad features assigned to hydrated species (ferrihydrites) as discussed below.

The particles of samples FENA1-3 are spherical and submicrometric. The spheres observed are nanocomposites made of the iron salts and the sodium salts (Figure 2b). For sample FENA3, obtained with the Fe:Na ratio $1: 5$, some $\mathrm{NaCl}$ cubic-like aggregates are also observed. These cubic aggregates are no more observed after washing the sample in water. After wash, highly porous aggregates, retaining the spherical shape of the nanocomposite particles are observed by TEM for FENA1 (Figure 2d), but hardly seen for FENA2,

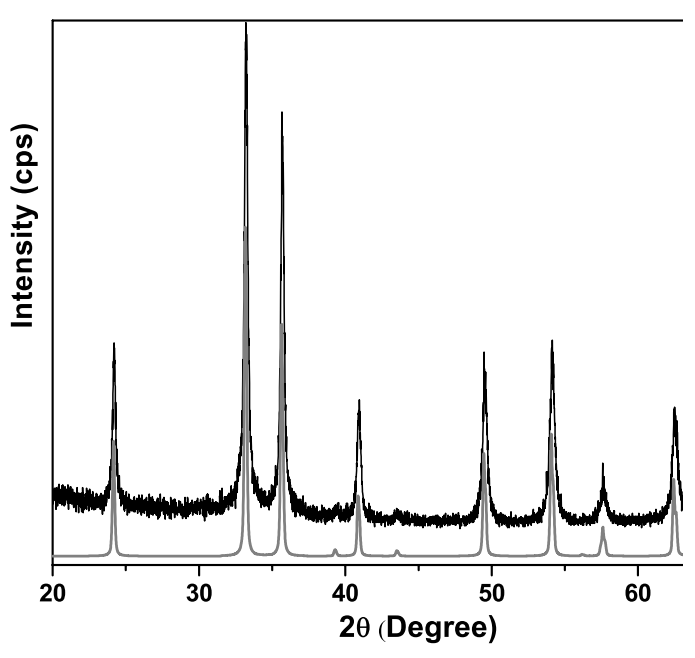

FIG. 3: XRD analysis. Sample FE1 and calculated diagram for hematite $\alpha-\mathrm{Fe}_{2} \mathrm{O}_{3}$.

washed (Figure 2c), same for FENA3 washed (not shown). These observations suggest first that at higher $\mathrm{T}_{\text {syn }}$, (820 for SPNA1 versus $660 \mathrm{~K}$ for SPNA2), the individual nanoparticles start to coalesce during the spray pyrolysis, and the formation of necks prevents desagglomeration of the spheres during washing. Another important parameter is the $\mathrm{Fe}: \mathrm{Na}$ ratio in the precursor: despite of being obtained at $\mathrm{T}_{\text {syn }}=820$ $\mathrm{K}$, aggregates of nanoparticles in FENA3 after wash are no more spherical, suggesting that the high $\mathrm{NaCl}$ concentration has not allowed enough contact among iron-based nanoparticles so that necks could not be formed prior to dissolution of the $\mathrm{NaCl}$ flux. Therefore, by carefully adjusting Fe:Na ratio and furnace temperature, sub-micronic spheres of iron oxides nanoparticles can be obtained through spray pyrolysis. The $\mathrm{N}_{2}$ adsorption-desorption isotherms of samples FENA1 (washed) have been measured: it comes that the surface area is $140 \pm 15 \mathrm{~m}^{2} / \mathrm{g}$. Compared to sample FE1, the XRD pattern recorded for sample FENA1 after wash exhibits significantly broadened peaks which can be assigned to poorly crystalline ferrihydrite, superimposed to the narrower diffraction peaks of hematite. Hematite is the end-product of thermal decomposition of the complex ferrihydrite. At same $\mathrm{T}_{\text {syn }}(820$ $\mathrm{K})$, the reaction is then less completed following the fluxassisted SP process than following the more conventional one phase SP. A more precise and quantitative description of the phases present in the SPNA1, after wash, has been achieved. A precisely weighted standard $\left(\mathrm{CeO}_{2}\right.$ at $\left.11.4 \% \mathrm{w} / \mathrm{w}\right)$ has been added to the sample in order to normalize the different fractions calculated by Rietveld analysis routine. In this model (from references [13, 14]), the structure of ferrihydrite is considered as being a superposition of two components: a defect-free phase of trigonal space group (P-31c) and a defective phase with a trigonal P3 space group. Rietveld analysis results are presented in Table II and in Figure 4: besides 27 weight $\%$ of hematite and 32 weight $\%$ of ferrihydrite, it is concluded that 41 weight $\%$ of the sample are amorphous. Taking the general formula $5 \mathrm{Fe}_{2} \mathrm{O}_{3}, 9 \mathrm{H}_{2} \mathrm{O}$ for the ferrihydrite, it comes from the Rietveld quantitative analysis that 5.4 weight $\%$ of the sample FENA1(washed) is $\mathrm{H}_{2} \mathrm{O}$. Experimentally, the total weight loss of the sample measured by 


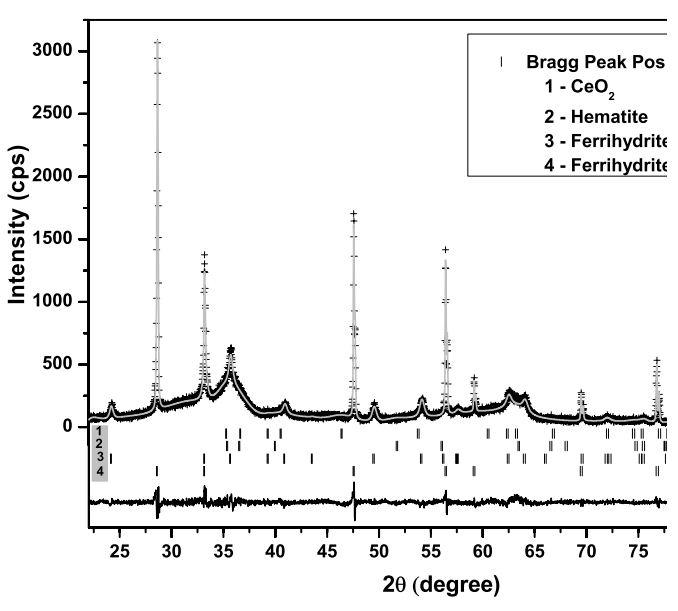

FIG. 4: XRD analysis.Sample FENA1 washed + internal standard $\mathrm{CeO}_{2}$; Rietveld simulation.

thermal analysis between 300 and $920 \mathrm{~K}$ is $7 \pm 0.14$ weight $\%$, which is consistent with the previous estimation. In turn, it proves that the composition of the amorphous phase is anhydrous $\mathrm{Fe}_{2} \mathrm{O}_{3}$.

\begin{tabular}{|c|c|c|c|c|}
\hline phase & amorphous & HEM & FEH(P3) & FEH (P-31c) \\
\hline weight $\%$ & 41 & 27 & 11 & 21 \\
\hline $\mathrm{H}_{2}$ Oweight $\%$ & - & - & 1.85 & 3.55 \\
\hline
\end{tabular}

TABLE II: sample FENA1 (washed): Refined phases weight $\%$ HEM $=\alpha-\mathrm{Fe}_{2} \mathrm{O}_{3}, \mathrm{FEH}=$ ferrihydrite

\section{B. Aluminium oxyhydroxides and oxides.}

The synthesis method selected to elaborate by SP the aluminium based samples is in fact the fast drying of a colloidal solution of boehmite, in order to stop the sol-gel process prior to the long range ordering of the solid phase. The elaboration conditions, the crystal phases identified and some typical properties of the samples are gathered in table III. As for the previous case, the SP synthesis produces NPs agglomerated in sub-micronic spheres. The measured surface area is high: $180 \pm 15 \mathrm{~m}^{2} / \mathrm{g}$ (sample AL200). The sample elaborated at the lower temperature (AL200) exhibits the XRD pattern of nanocrystalline boehmite $\gamma-\mathrm{AlOOH}$ (Figure 5). It may be spontaneously dispersed in water. In ref.[5] we have shown that the rapid drying (a few seconds) of the sol stops the development of the aluminium hydroxide network at the level of a few crystal cells. Half the hydroxyl groups are in fact at the external surface of the crystallites. This resulted in a very large number of surface hydroxyls free for water adsorption, actually the chemical composition of SP nano crystallized boehmite is $\mathrm{AlOOH},(1.18 \pm 0.24) \mathrm{H}_{2} \mathrm{O}$. The very hydrophilic nature of the surface of SP- boehmite crystallites is at the origin of their ability to form stable suspensions in water. When the synthesis is performed at higher temperature (AL700), the XRD peaks are still broader and fit well with what is reported in literature as the transition alumina $\gamma-\mathrm{Al}_{2} \mathrm{O}_{3}$. AL700 powder precipitates in water. Nanocomposites obtained by reac-

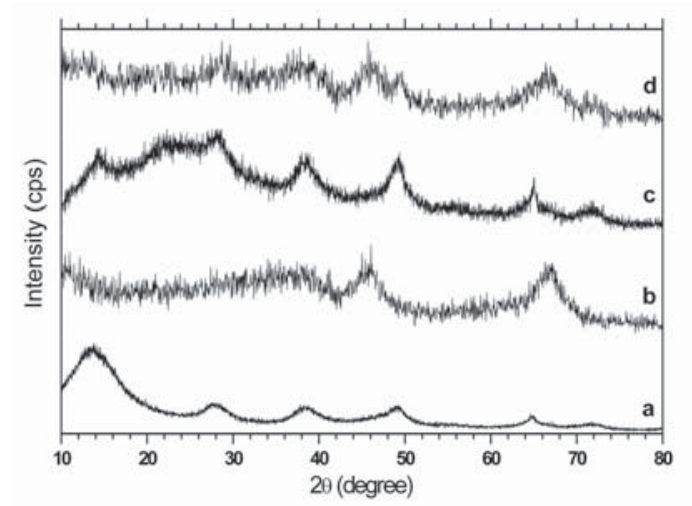

FIG. 5: XRD patterns of samples AL200 (a), AL700 (b), AL200ASN (c), AL700-ASN (d).

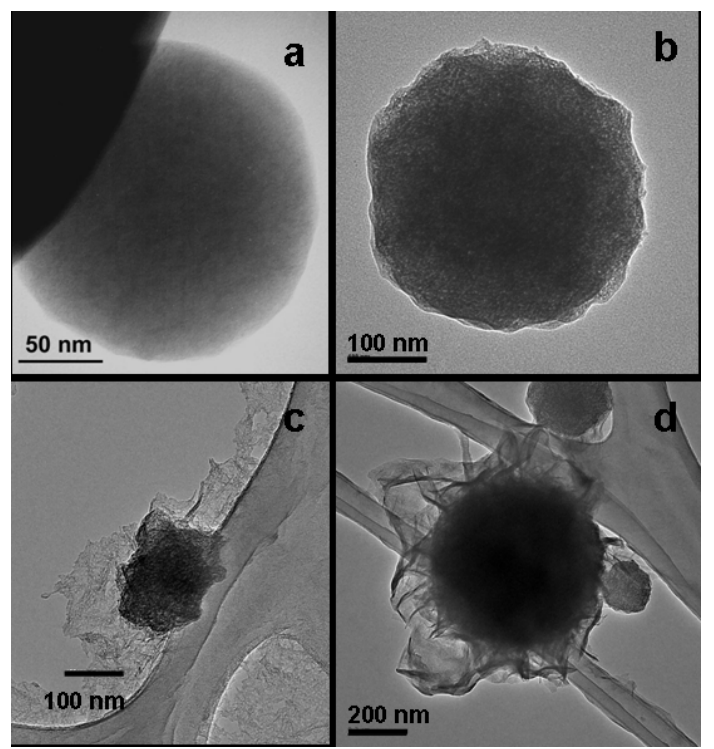

FIG. 6: TEM images of samples AL200 (a), AL700 (b), AL200ASN (c), AL700-ASN (d).

tion with ASN behave the same way with respect to dispersion. The interactions between the ASN and the particles surfaces are imaged in Figure 6. The AL200 (boehmite) spheres have a smooth surface (Figure 6a), whereas the Al700 ( $\gamma$ $\mathrm{Al}_{2} \mathrm{O}_{3}$ ) are less regular, and denser (Figure 6b). After reaction with $\mathrm{ASN}$ at molar ratio $\mathrm{ASN}: \mathrm{Al}=0.3: 1$ and drying, most of the boehmite spheres have disaggregated and the sample looks like a film in which are dispersed nanoparticles. Aluminium is identified by local analysis (EDXS in TEM) for all parts of the film, and the XRD is that of boehmite. The TEM image selected here (Figure 6c) shows the composite film and one mineral bigger particle not completely destroyed. For the transition aluminas AL700-ASN (Figure 6d), the mixing of the ASN and of the mineral part is less intimate: one observes an organic film wrapping the sub micronic $\gamma-\mathrm{Al}_{2} \mathrm{O}_{3}$ particles.

The peculiar emission of $\mathrm{Eu}^{3+}$ in AL200: $\mathrm{Eu}$ (atomic ratio $\mathrm{Eu}: \mathrm{Al}=0.02: 1)$ is very well preserved in the composite Al200:Eu-ASN (Eu:Al = 0.02:1, ASN:Al =0.3:1) displayed in Figure 7a. In the same way, the emission spectra of $\mathrm{Eu}^{3+}$ in A1700:Eu and in A1700:Eu-ASN samples are very similar (the last one displayed in Figure 7b). One recognizes easily 


\begin{tabular}{|c|c|c|c|c|}
\hline sample & XRD & $\mathrm{T}_{\text {syn }}$ & morphology & water dispersion \\
\hline AL200 & BOEH & 470 & $\begin{array}{c}\text { spheres, } \\
\text { sub- } \mu \mathrm{m}\end{array}$ & stable \\
\hline AL700 & TA & 970 & $\begin{array}{c}\text { spheres, } \\
\text { sub- } \mu \mathrm{m}\end{array}$ & precipitated \\
\hline AL200-ASN & BOEH & - & $\begin{array}{c}\text { organic film + } \\
\text { BOEH NPs }\end{array}$ & stable \\
\hline AL700-ASN & TA & - & $\begin{array}{c}\text { spheres + } \\
\text { film at surface }\end{array}$ & precipitated \\
\hline
\end{tabular}

TABLE III: Aluminium-based samples : synthesis temperature $\mathrm{T}_{\text {syn }}$ $(\mathrm{K})$, crystalline phases $\mathrm{BOEH}=\boldsymbol{\gamma}-\mathrm{AlOOH}, \mathrm{TA}=\boldsymbol{\gamma}-\mathrm{Al}_{2} \mathrm{O}_{3}$, morphology and stability in water.

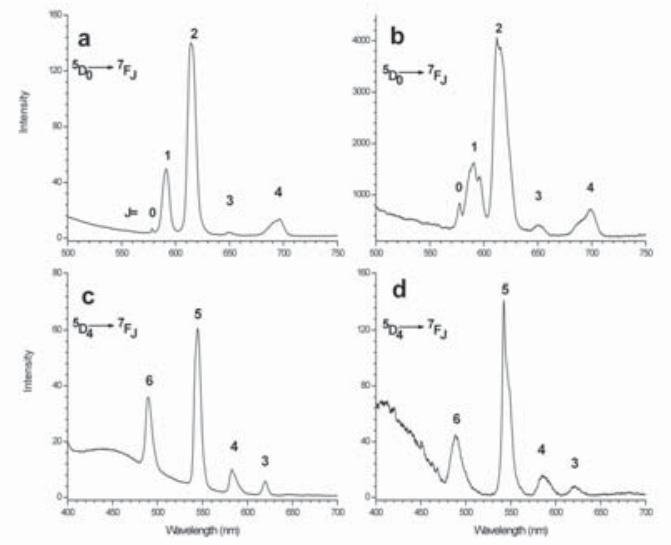

FIG. 7: Photoluminescence emission spectra recorded at room T, spectral resolution $2.5 \mathrm{~nm}$. Excitation at 394nm, samples A1200:EuASN (a) and Al700:Eu-ASN (b); excitation at 250nm, samples Al200:Tb-ASN(c) and Al700:Tb-ASN (d)

the well known ${ }^{5} \mathrm{D}_{0} \rightarrow{ }^{7} \mathrm{~F}_{0-4}$ emissions in the visible wavelength range for both samples, the changes observed in the details of the spectra exemplify the possibility to make use of $\mathrm{Eu}^{3+}$ as a local structural probe. $\mathrm{Eu}^{3+}$ in $\gamma-\mathrm{Al}_{2} \mathrm{O}_{3}$ exhibits larger splitting than in $\gamma$-AlOOH for all the transitions (particularly visible for ${ }^{5} \mathrm{D}_{0} \rightarrow{ }^{7} \mathrm{~F}_{1}$ ), which traduces that the average crystal field acting on $\mathrm{Eu}^{3+}$ is higher in the case of $\gamma$ $\mathrm{Al}_{2} \mathrm{O}_{3}$. The $\mathrm{Eu}^{3+}$ excitation spectra (not shown here) exhibit the intra- $4 \mathrm{f}^{6}$ narrow excitation lines and a broad absorption to the $\mathrm{Eu}-\mathrm{O}$ charge transfer state (CTS). In $\gamma-\mathrm{Al}_{2} \mathrm{O}_{3}$, as it is observed also in most of the oxide matrices, excitation in CTS is more powerful than intra- $4 \mathrm{f}^{6}$ excitation, but it is remarkably inefficient in $\gamma$-AlOOH. It is not clear if the band shifts at lower wavenumbers for the boehmite samples or if absorption to the CTS is simply less intense, in any case this effect traduces that the oxygen to metal interaction is weaker in doped boehmite than it is in doped $\gamma-\mathrm{Al}_{2} \mathrm{O}_{3}$. The third point is that the ${ }^{5} \mathrm{D}_{0} \rightarrow{ }^{7} \mathrm{~F}_{0-4}$ emissions are in-homogeneously broadened in transition alumina, much more than in boehmite, showing that the $\mathrm{Eu}^{3+}$ ions are in numerous different environments in the highly porous $\gamma-\mathrm{Al}_{2} \mathrm{O}_{3}$.

These spectroscopic characteristics have been interpreted in $[4,5]$ as follows: partly hydrated europium ions are di- rectly bonded to $\mathrm{OH}$ groups at the boehmite surface, and are well maintained at the NPs surface in the nanocomposites. In the transition alumina, $\mathrm{Eu}^{3+}$ ions enter (at least partly) the structure and are linked via $\mathrm{Al}-\mathrm{O}-\mathrm{Eu}$ bonds. The interaction with ASN does not modify the spectra. Terbium $\left(\mathrm{Tb}^{3+}\right)$ is also well known to be a good photoluminescent emitter in the green range $(540 \mathrm{~nm})$. We have synthesized and investigated the analogous nanocomposites with this ion: Al200:Tb-ASN (Tb:Al = 0.02:1, ASN:Al =0.3:1) and Al700:Tb-ASN. The corresponding emission spectra are recorded in Figure $7 \mathrm{c}$, and $\mathrm{d}$, respectively. There is no difference between the two spectra because $\mathrm{Tb}^{3+}$ is not really a good structural probe at the low spectral resolution employed here. Due to the similarities of chemical properties along the lanthanides series, it seems reasonable to assume that $\mathrm{Tb}^{3+}$ ions behave the same way that $\mathrm{Eu}^{3+}$ ions as for their interaction with the aluminium oxide matrix and with the ASN. Further work is in progress because in fact it appears that the physico-chemical interactions in the ternary systems aluminate (boehmite or transition alumina) - lanthanide - ASN are not exactly the same for the two lanthanides $\mathrm{Eu}$ and $\mathrm{Tb}$. Nevertheless it may be noticed that luminescent nanocomposites emitting in the green range and stable in water may be obtained from SP synthesis.

\section{CONCLUSION}

We have shown how Spray Pyrolysis conducted at moderate temperature (from 470 to $970 \mathrm{~K}$ in the decompositiondensification area) may be employed for the synthesis of highly divided, highly reactive metal (here $\mathrm{Fe}$ or $\mathrm{Al}$ ) hydroxides and oxides powders. Two different synthesis strategies have been explored. In the case of iron-based oxides, a soluble flux $(\mathrm{NaCl})$ has been added to the precursor $\left(\mathrm{Fe}\left(\mathrm{NO}_{3}\right)_{3}\right)$ in water solution. Under controlled synthesis conditions, after removal of the flux, nanocomposites of ferrihydrite $\left(5 \mathrm{Fe}_{2} \mathrm{O}_{3}, 9 \mathrm{H}_{2} \mathrm{O}\right) /$ hematite $\alpha-\mathrm{Fe}_{2} \mathrm{O}_{3} /$ and an amorphous $\mathrm{Fe}_{2} \mathrm{O}_{3}$ are obtained, with surface area $140 \mathrm{~m}^{2} / \mathrm{g}$. In the case of aluminium-based oxides, an Al-alcoholate precursor has been preferred, in order to get only the boehmite $\gamma-\mathrm{AlOOH}$ (at the lower temperature) or the transition alumina $\gamma-\mathrm{Al}_{2} \mathrm{O}_{3}$. Boehmite powders are obtained with surface area equal to $140 \mathrm{~m}^{2} / \mathrm{g}$ that can be easily dispersed in water. Nanocomposites made by reaction of the boehmite or $\gamma-\mathrm{Al}_{2} \mathrm{O}_{3}$ particles with the amino acid asparagin (ASN) have been investigated. These nanocomposites have been doped with a lanthanide ion $\left(\mathrm{Eu}^{3+}\right.$ or $\left.\mathrm{Tb}^{3+}\right)$, and their luminescence investigated since they can be considered as bio-compatible luminescent nanoparticles.

\section{Acknowledgments}

The authors acknowledge the FAPESP, and the CAPESCOFECUB Brazil-France cooperation program for financial support. 
A.Garcia, P. Guillot, J. Galy, R. Mauricot and S. Schamm, J. Phys. D. 38, 3261 (2005).

[3] C. Rossignol, M. Verelst, J. Dexpert-Ghys and S. Rul, Adv. Sci. Tech. 45, 237 (2006).

[4] J.M.A. Caiut, J. Dexpert-Ghys, Y. Kihn, M. Verelst, H. Dexpert, S.J.L. Ribeiro and Y. Messaddeq, Powder Techn. 190 , 95-98 (2009).

[5] J.M.A. Caiut, S.J.L. Ribeiro, Y. Messaddeq, J. Dexpert-Ghys, M. Verelst and H. Dexpert, Nanotech. 18, 455605 (2007).

[6] J.M.A. Caiut, L. Bazin, R. Mauricot, H. Dexpert, S.J.L. Ribeiro and J. Dexpert-Ghys, J. Non Cryst. Sol. 35, 4860-4864 (2008).

[7] F. Schuth, Chem. Mater. 13, 3184 (2001).

[8] D. G. Rancourt, D. Fortin, T. Pichler, P.J. Thibault, G. Lamarche, R.V. Morris and P.H.J. Mercier, Am. Mineral. 86, 834 (2001).

[9] U. Schwertmann, L. Carlson and E. Murad, Clays Clay Miner. 35, 297 (1987).

[10] Y. Jia, L. Xu, X. Wang and G.P. Demopoulos, Geochim. et Cosmochim. Acta 71, 1643 (2007).

[11] R.L. Penn, Science 316, 1704 (2007).

[12] F.M. Michel, L. Ehm, S.M. Antao, P.L. Lee, P.J. Chupas, G. Liu, D.R. Strongin, M.A. A. Schoonen, B.L. Phillips and J.B. Parise, Science 316, 1726 (2007).

[13] E. Jansen, A. Kyek, W. Schfer, U. Schwertmann, Appl. Phys. A, 74, 1004 (2002).
[14] Y. Cudennec, A. Lecerf, J. Solid State Chem. 179, 716 (2006).

[15] R.M. Cornell and U. Schwertmann, The Iron Oxides, Structure, Properties, Reactions, Occurrence and Uses (WCH, Weinheim, New York, Basel, Cambridge, Tokyo, (2004)).

[16] A. Pearson, Aluminium oxide, activated, in Kirk-Othmer Encyclopedia of Chemical Technology (J. Wiley, New York, 2, 291 (1994)).

[17] C. Misra, Aluminium oxide, hydrated, in Kirk-Othmer Encyclopedia of Chemical Technology (J. Wiley, New York, 2, 317 (1994))

[18] B. E. Yoldas, Ceramic Bull. 54:3, 289 (1975).

[19] B. E. Yoldas, J. Mater. Sci. 10, 1856 (1975).

[20] M. Nguefack, S. Rossignol, A.F. Popa, and C. Kappenstein, Phys. Chem. Chem. Phy. 5, 4279 (2003).

[21] R.S. Zhou, R.L. Snyder, Appl. Crys. 47, 617 (1991).

[22] K. \& MISRA, C.. Alcoa Technical Paper 19, revised. Alcoa Laboratories, Pittsburg, PA, USA. (1987)

[23] H.M. Rietveld, J. Appl. Crystall. 2, 65 (1969).

[24] A.C. Larson and R.B. Von Dreele, Los Alamos National Laboratory. Los Alamos , EUA. Copyright, 1985-2000, The Regents of the University of California, 2001.

[25] N. Reuge, J. Dexpert-Ghys, M. Verelst, H. Dexpert and B. Caussat, AlChE J. 54, 394 (2008). 